\title{
Recent Advances in Blast Furnace Ironmaking Technology in Australia
}

\author{
J.M. BURGESS \\ BHP Central Research Laboratories, Wallsend, NSW 2287, Australia. \\ (Received on October 19, 1990; accepted in the final form on February 22, 1991)
}

This review presents some of the recent advances in ironmaking technology in Australia. The first part of the paper summarises blast furnace operations in terms of productivity, fuel rate and hot metal chemistry in BHP. It is shown that in the recent past Australian furnace operations have been characterised by high productivity and low fuel rate. In the second part of the review, the main blast furnace research and development topics are presented. The first of two research streams, which is shorter term in focus, is associated with the development and implementation of computer models and associated sensors to assist present operations. Some of the developments which are reviewed in this field include burden distribution studies, models of the momentum, heat and mass transfer processes occurring in the furnace, raceway studies, opto-electronic and other sensor developments, and studies associated with hearth liquid drainage. The second stream, which addresses longer term strategies, is associated with studies on future blast furnace operations. In this stream, research work on the combustibility of pulverised coals in the blast furnace environment is described. The results shown indicate that Australian research has made a substantial contribution to knowledge in blast furnace ironmaking, and that the studies undertaken are of considerable benefit to Australian blast furnace operations.

KEY WORDS: ironmaking; blast furnace process; research and development; Australia; burden distribution; computer models; probes; lasers; sensors; raceway; hearth drainage; pulverised coal injection; combustion.

\section{Introduction}

Six blast furnaces are operated in Australia at the present time: three at Port Kembla, two at Newcastle, and one at Whyalla. The Port Kembla and Newcastle furnaces are operated with a burden comprising sinter (70\% of the burden), lump ore (15 to $20 \%$ ) and pellets (10 to $15 \%$ ). The Whyalla furnace uses local fluxed pellets ( $70 \%$ of the burden) and lump ore $(30 \%)$. Operations of these furnaces have been reported by Platt et al. ${ }^{1)}$, Fletcher et al. ${ }^{2)}$, and Ward et $a .^{3)}$, respectively.

Australian blast furnaces are generally operated at relatively high productivity and low fuel rates. For example, Port Kembla No. 5 furnace is a high top pressure, bell-less top furnace with three tapholes and an inner volume of $3045 \mathrm{~m}^{3}$. The present campaign of this furnace commenced in December 1978 and the furnace has since produced 25 million $t$ of iron. Fig. 1 shows the performance indices for the furnace since 1983. As can be seen, productivity expressed in terms of furnace inner volume increased significantly between 1983 and 1986, with values in the later part of this period being approximately $2.3 \mathrm{t} / \mathrm{m}^{3}$ inner volume/d (equivalent to $2.6 \mathrm{t} / \mathrm{m}^{3}$ working volume/d). This furnace experienced an ingress of water in late 1987 due to tuyere failure and a recovery period of several months ensued. Productivity since that time has improved back to levels as high as $2.4 \mathrm{t} / \mathrm{m}^{3}$ inner volume $/ \mathrm{d}$. Overall fuel rate fell from approximately $550 \mathrm{~kg} / \mathrm{t}$ in 1983 to $450 \mathrm{~kg} / \mathrm{t}$ in 1986 , with coke rates as low as $410 \mathrm{~kg} / \mathrm{t}$. Natural gas rates in 1986 were up to $43 \mathrm{~kg} / \mathrm{t}$ with approximately $2 \%$ oxygen enrich- ment. The furnace has stabilised recently with fuel rates of $475 \mathrm{~kg} / \mathrm{t}$. Hot metal chemistry expressed in terms of silicon content showed a decrease to levels lower than $0.4 \%$ from 1983 to 1986 . Since then the silicon content has been between 0.4 and $0.5 \%$.

Raw materials properties for this furnace also underwent a significant change during the period under review. The iron content of the sinter increased during 1983-85 from 53 to $56 \%$, and a greater proportion of high quality pellets was used. In addition, coke ash was reduced from 13.5 to $12 \%{ }^{4}$ ) These changes led to a decrease in slag volume from 370 to $290 \mathrm{~kg} / \mathrm{t}$, with corresponding improvements in casting practice. The increase in productivity evident in Fig. 1 during this period was due both to these improvements in raw materials quality and improved operating practice.

At the Newcastle blast furnaces, high levels of oxygen enrichment (up to $7 \%$ of the blast volume) and natural gas (up to $90 \mathrm{~kg} / \mathrm{t}$ ) are used. It is also noteworthy that both the Newcastle furnaces recently had a second taphole installed during operation to improve hearth drainage, and this was a world first. At Whyalla very stable operations on a single furnace at similar high productivity levels have been obtained with high pellet proportions in the burden. ${ }^{3)}$ This furnace has also achieved a total production of over $5000 \mathrm{t} / \mathrm{m}^{3}$ of inner volume during its present campaign.

\section{Ironmaking Research and Development}

Ironmaking research and development in Australia 

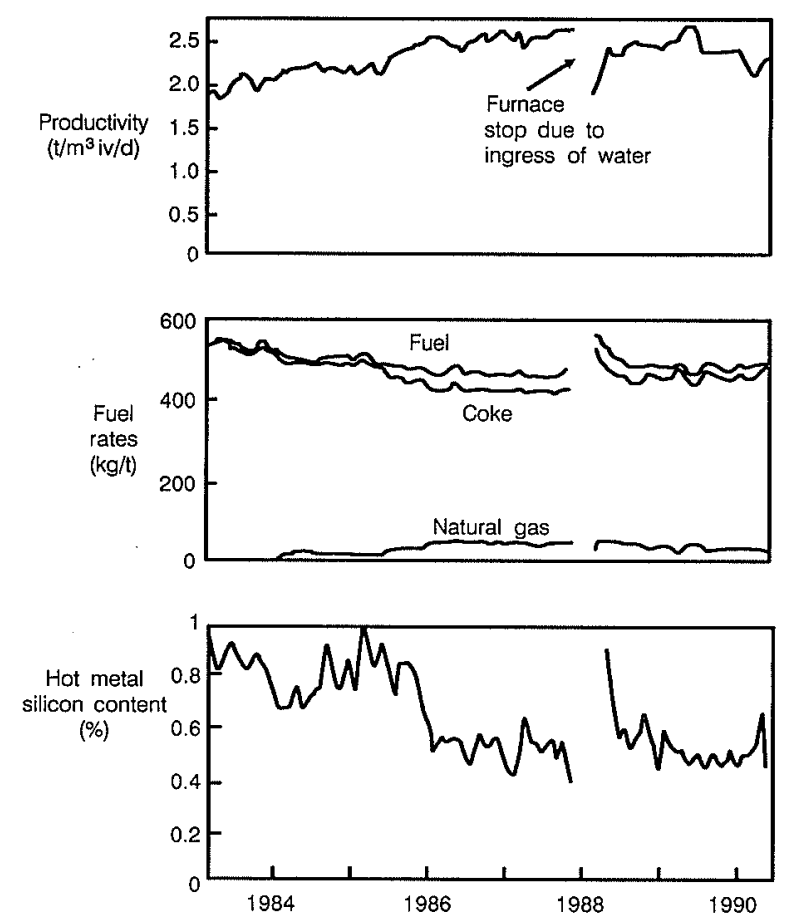

Fig. 1. Productivity, fuel rates and hot metal silicon content at Port Kembla No. 5 blast furnace in 19831990.

is primarily carried out by $\mathrm{BHP}$, with a small part of the research also being carried out by Universities. Some of the main research areas have been the use of computer models and associated measurement of burden distribution parameters, the development of coupled momentum, energy, and chemical reaction rate models, fundamental raceway studies, the development of opto-electronic sensors to measure both the furnace stockline contours and the state of the raceway zone, fundamental studies on blast furnace hearth liquid drainage and examination of the combustibility of a range of different pulverised coals in high temperature equipment. In the review which follows, each of the above areas is considered in more detail.

\subsection{Burden Distribution}

Burden distribution and its control play a central part in the optimisation of a variety of factors, including energy efficiency, productivity, furnace lining life and control of the desired metal chemistry.

To assist in the analysis of burden distribution, a burden distribution numerical model was purchased from Nippon Steel Corporation in 1986. This model is called the "RABIT" model ("RAdial Burden distribution Index by Theory" ). ${ }^{5-7)}$ The model computes the relative amounts of ore and coke as well as particle size and the isothermal gas flow distribution in the furnace shaft as a function of radial position. In Australia experimental simulations of both Port Kembla No. 5 blast furnace and Newcastle No. 4 furnace were conducted with the use of full scale model $s^{8)}$ and information from these studies enabled the RABIT model to be customised to local conditions.

Fig. 2 shows typical measurements of the variation

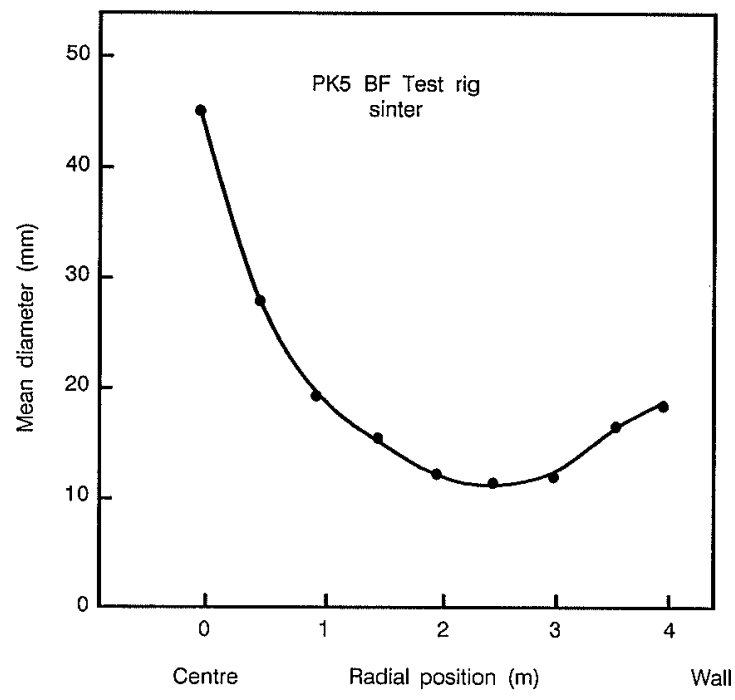

Fig. 2. Typical measured variation of sinter particle size as a function of radial position from a full scale Port Kembla No. 5 bell-less top burden distribution test.

of particle size as a function of radial position from a full scale Port Kembla No. 5 bell-less top burden distribution test. The materials were sampled using a novel technique whereby plaster of Paris was poured into the bed of sinter through an annular ring to form a series of sub-surface, in-situ sampling cylinders along the radius. It can be seen that the particle size is at a minimum at a point towards the wall, and that the particles are relatively large at the wall and at the centre. The results obtained in these experiments depend on the charging conditions, including the angle settings and discharge conditions on the rotating chute. The RABIT model incorporates results such as those shown in Fig. 6 using the size classification theory developed by Miwa. ${ }^{9}$ (Data were also obtained from this equipment on angles of repose, falling stream trajectories and coke collapse. ${ }^{5-8)}$

The RABIT model was employed to predict the relative radial gas distribution conditions on both Newcastle No. 3 furnace and Port Kembla No. 5 furnace. ${ }^{8)}$ For example, at Newcastle No. 3 furnace the model was used during 1986 to review various charging sequences with the aim of achieving a reduction in the wall heat loads and an acceptable radial ore thickness ratio distribution. The model prediction was compared with the furnace operating data using relative gas velocity indices generated from the above burden temperature distributions. As shown in Fig. 3, the model predicted increased central gas flow and reduced wall flow as a result of the changes in burden distribution. In general, the RABIT model predictions were in good agreement with the furnace trends, and the overall furnace performance was improved through adjustment of gas distribution.

Fundamental studies allied to burden distribution have also been carried out at the University of Wollongong. These have included studies on the permeabilities of particle mixtures ${ }^{10-15)}$ and in bins during discharge to bell-less top chutes. ${ }^{16-19)}$ The particle permeability work involved experimental 

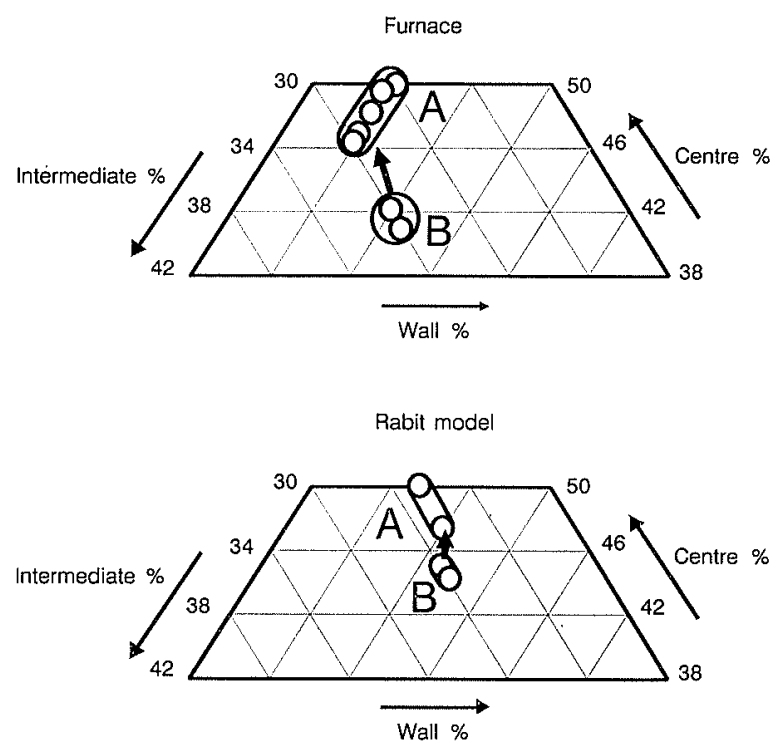

Fig. 3. Comparison of relative gas flow distribution indices calculated from both the RABIT model and above burden temperature distributions for Newcastle No. 3 blast furnace.

studies on the void fraction and pressure losses of beds of ternary mixtures for both spherical and irregular particles. Studies were also conducted on the structure and permeability of bell-less top charged sinter layers, concentrating on the decreased permeability of the mixed zone between the sinter and coke layers. The studies on the size segregation during the discharge of a bell-less top hopper involved 1/15th scale model experiments using coke and sinter. In-bin segregation and tracer flow patterns and residence time distributions were measured in this work and the results indicated that small particles segregated in the centre, large particles segregated towards the wall and medium sized particles remained essentially unsegregated during discharge.

\subsection{Momentum, Heat and Mass Transfer Modelling}

\subsubsection{Outline of the Model}

It is apparent that phenomena occurring in the blast furnace are closely coupled and a model which attempts to simulate the internal state of the furnace must take into account all the important parameters simultaneously. These will include both radial and axial gas flow under the influence of non-uniform permeability distributions, the solid flow patterns, the heat transfer between the counter-flowing phases and the dependence of the chemical reaction rates on the temperature and gas composition profiles. A model of this type was recently developed and predictions from the model on the theoretical influence of burden distribution on furnace temperature and gas composition distributions were reported by Burke and Burgess. $^{20)}$ A recent implementation of the model to Port Kembla No. 5 blast furnace was discussed by Tanzil et al. ${ }^{21)}$

In the present review, development of the model itself is not discussed in detail. Rather, stress is placed on the application of the model to furnace op- erations and comparisons between the model predictions and the observed furnace behaviour. Important features of the model are:

(i) Solid flow is calculated using potential flow theory, with flows of coke and ore being solved separately, and coke flowing around the deadman at the centre of the furnace.

(ii) Gas flow is compressible, with density changing as a function of both gas temperature, gas pressure and gas composition. Pressure loss and the corresponding gas velocity vectors are calculated through application of the well known Ergun relationship ${ }^{22)}$ in two dimensions.

(iii) Heat transfer between the two counter-flowing phases is calculated using the Ranz relationship ${ }^{23)}$ with empirical modification introduced by Hatano and Kurita. ${ }^{24)}$ Heat evolution or absorption due to chemical reactions is taken into account according to the local reaction rates.

(iv) Gas compositions are calculated according to the local chemical reaction rates, these being taken from a variety of published sources. ${ }^{25-27)}$ The reduction reactions of hematite, magnetite and wustite by both carbon monoxide and hydrogen are taken into account, together with the solution loss and water gas shift reactions.

(V) Ferrous burden is assumed to soften at 1200 ${ }^{\circ} \mathrm{C}$ and to melt at $1400^{\circ} \mathrm{C}$. A linear decrease in ferrous layer void fraction is assumed between these two temperatures, and anisotropic permeability relationships are employed to compute the local gas flows in the cohesive zone region.

\subsubsection{Application to Operating Furnaces}

During early May 1989, an unusual inactive buildup developed in the lower shaft of Port Kembla No. 5 furnace. To rectify this, the wall gas flow was progressively increased by the gradual reduction of ore layer thickness at the wall. This led to removal of the buildup. Following a period of shutdown for routine maintenance, furnace operations then became unstable, with excessive wall heat loads. At this point the burden distribution was changed to reduce the wall gas flow and stabilise operations. Later, the burden distribution was adjusted to maintain sufficient wall gas flow to keep the wall clean and active, while uprating the ore-to-coke ratio and the production rate. During this whole period, which lasted approximately 40 days, the two-dimensional model was used to visualise the inner state of the furnace and to provide information for operators.

Fig. 4 shows 10 predictions from the model in terms of solid temperature distributions for the 10 separate burden distributions employed on Port Kembla No. 5 furnace during the period mentioned above. ${ }^{21)}$ The region between 1200 and $1400^{\circ} \mathrm{C}$ is shown highlighted, since this is the zone in which the ferrous materials soften and melt and which governs the gas flow patterns in the lower zone of the furnace. As can be seen, there is progressive movement from a "W" shaped cohesive zone, through a " $\mathbf{U}$ " shape when wall flow is increasing, to a relatively high, flat 


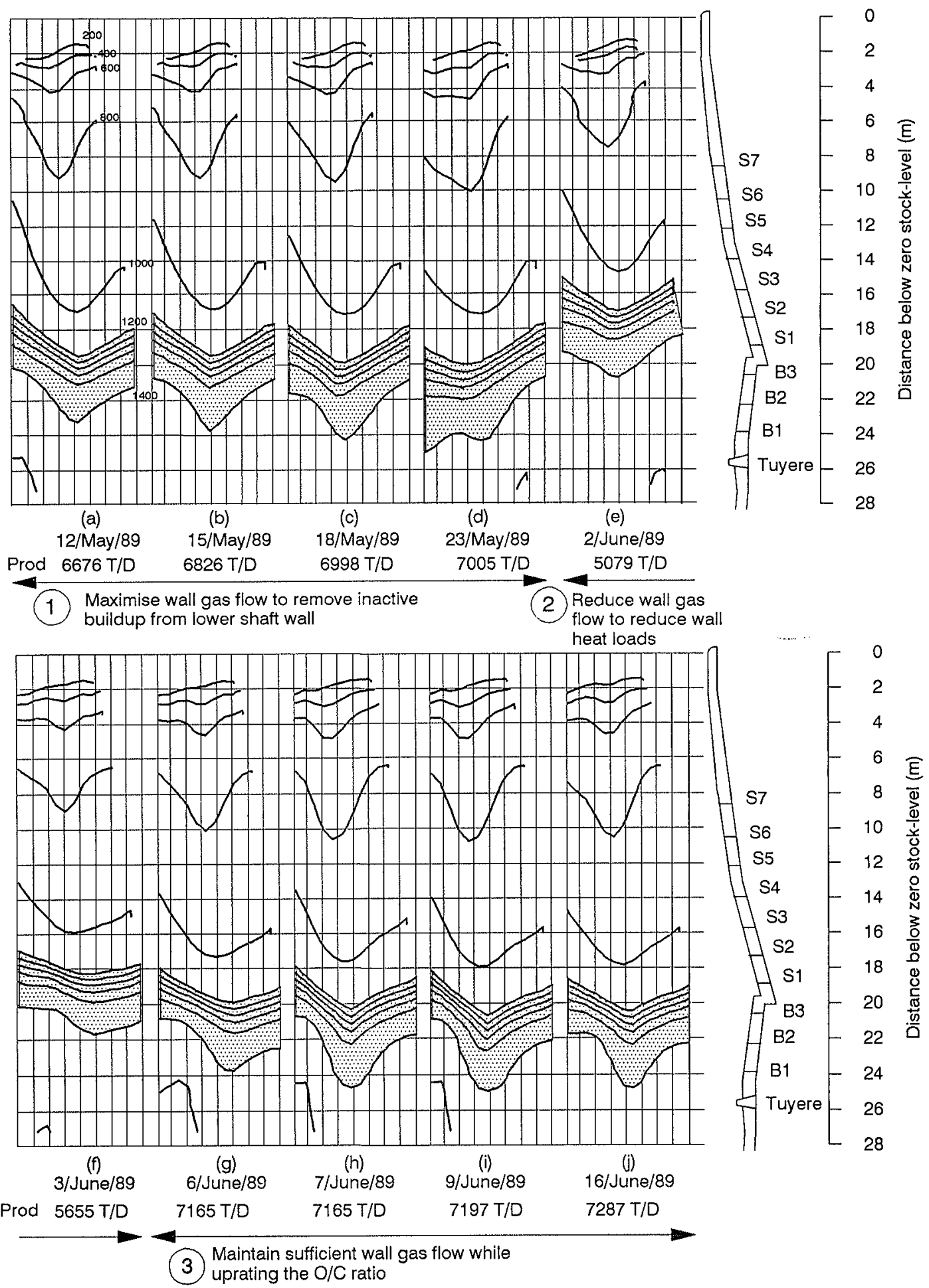

Fig. 4. Predicted solid temperature isotherms and cohesive zone shapes for Port Kembla No. 5 blast furnace during May-June 1889 for 10 different burden distribution periods.

zone, and finally a " $\mathbf{W}$ " shaped zone with a pronounced droop at the mid-radial position.

The gas flow patterns associated with these zones as predicted by the model are shown in Fig. 5 in the form of gas velocity vectors. Here it may be seen that the gas flow patterns are predicted to change markedly as a function of the temperature patterns, with the final optimised flow pattern showing a bifurcated form around the drooping part of the melting isotherm. It is noteworthy that the highest production levels during the period under consideration were during this final phase, when the gas flows were predicted to divide between the centre and the wall as a consequence of the shape of the melting zone. This was also the period of greatest furnace stability and lowest hot metal silicon content.

\subsection{Raceway Studies}

Many studies of raceway behaviour involving the use of hot and cold models have been conducted, including several in Australia. ${ }^{28-32)}$ Fundamental cold model studies were carried out at the University of 


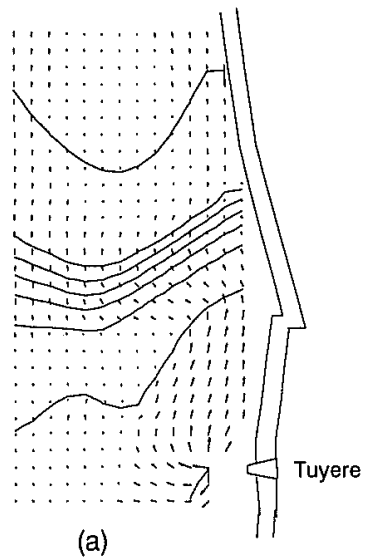

(a)

7005 T/Day

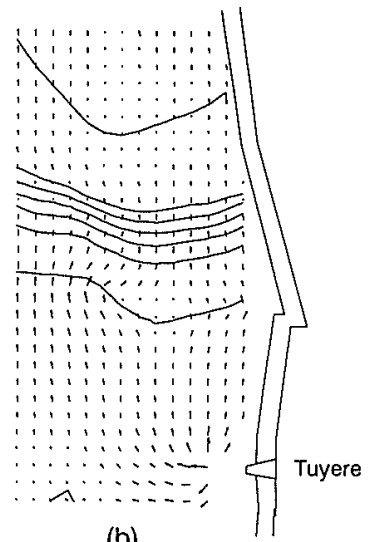

(b)

$3 /$ June/89

5655 T/Day

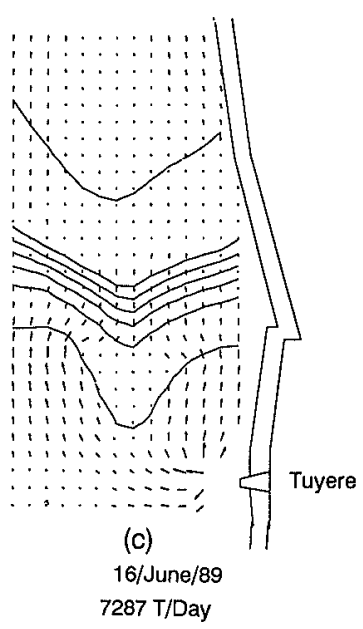

Fig. 5.

Predicted gas velocity vectors for three of the cases shown in Fig. 4.
Newcastle by Apte et al. ${ }^{29,30)}$ and, at BHP, a hot model was employed by McCarthy et al. ${ }^{31,32)}$ to assess the influence of coke quality and air blast conditions on the size and extent of the raceway.

The first of the cold model studies involved measurements of the pressure distribution along the boundary of the raceway cavity in a two-dimensional bed and calculation of the gas velocities exiting the cavity. ${ }^{29)}$ These were then compared with a mathematical model. It was found from this work that the presence of solids in the raceway cavity is important in distributing the gas jet transversely, and that the resistance to the flow of gas through the packed bed surrounding the raceway plays a major role in determining the flow distribution through the boundary. In the second study ${ }^{30}$ the vertical stress profile in the packed bed above the raceway cavity was estimated by a force balance analysis and static bed measurements. Abrupt changes in the stress and the gas velocity were observed near the cavity roof and these were found to fluctuate vertically with the raceway size. The hot model work conducted by McCarthy et al. ${ }^{31,32)}$ was primarily directed towards understanding coke breakdown mechanisms and raceway size during coke combustion.

\subsection{Advanced Sensor Technologies}

Several specialised sensors based on opto-electronic technologies are presently being developed in Australia to assist in providing information to furnace operators. Lasers and fibreoptic devices have been used to develop sensors to assist the operators to monitor the state of the furnace and to provide data for the models mentioned previously. In particular, attention has been given to the development of methods for the measurement of raceway properties.

\subsubsection{Burden Profiling System}

Based on the acquired expertise from the optical stockrod system, a YAG laser profiling system using a $90^{\circ}$ field of view was developed. The system was installed recently on Newcastle No. 4 furnace during filling of the furnace before a blow-in. It was found that it was possible to measure to the bottom of the empty furnace prior to filling and to measure profiles
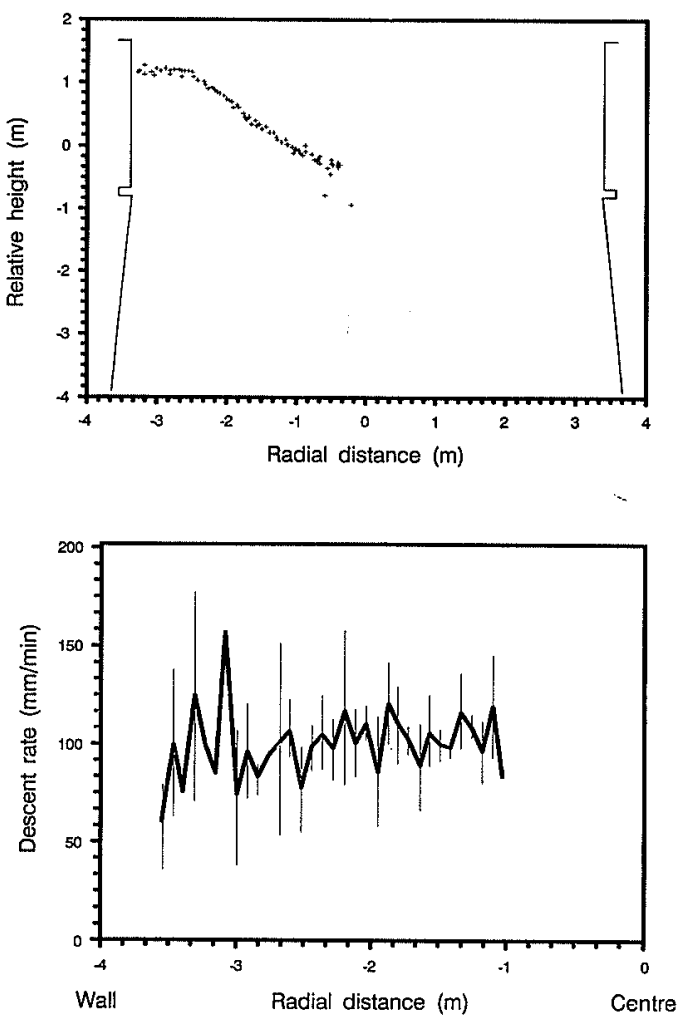

Fig. 6. Radial burden profile and burden descent speed distribution measured by a laser profiling system on Newcastle No. 4 blast furnace.

as the furnace was filled. More recently, the system was used during operation and a typical example of the radial profile obtained and the burden descent speed distribution is shown in Fig. 6.

\subsubsection{Raceway Monitoring System}

The system is based on Time of Flight (ToF) radar technology in which a laser pulse of short duration, typically a few nanoseconds, is transmitted to a target and the time of flight is used to measure the target range. On entering the raceway, laser radiation is predominantly scattered by fast-moving coke particles and only a small fraction of transmitted pulses penetrate to the back raceway wall. By choosing the laser pulse repetition rate and an appropriate wavelength of laser light, it is possible to measure the raceway 
depth about once every $10 \mathrm{~s}$. The system has been extensively tested in the laboratory using cold models, where the laser based measurements have been compared satisfactorily with physical measurements. It has also been applied for long periods on operating blast furnaces.

A schematic diagram of the measurement system is shown in Fig. 7 for a single tuyere. ${ }^{23)}$ The system consists of three sub-systems: an optical head, a light transmission and detection unit, and a signal processing and display unit. The measurements are made through a specially designed optical window assembly which fits on the furnace peepsight. The optical head transmits radiation from the nitrogen laser into the raceway and collects back-scattered radiation for transmission back to the detection unit. A fast shutter speed CCD camera provides frozen images of coke particles in the raceway and provision has also been made for operator inspection of the raceway using a side mounted view-port.

The optical head is linked to the transmission and detection unit by $20 \mathrm{~m}$ of armoured and sealed flexible conduit containing optical fibres. Raceway brightness is also measured in two spectral regions to provide a simultaneous measurement of raceway temperature. Although Fig. 7 shows the system for one tuyere, the system has been configured for the monitoring of circumferential non-uniformity of raceway conditions on four tuyeres simultaneously.

Fig. 8 shows typical results from the system over a $2 \mathrm{~h}$ period on Newcastle No. 3 blast furnace for one tuyere. During the period shown the furnace was taken off blast during the last $30 \mathrm{~min}$. The figure shows both the depth of the raceway (" maximum ") and the position at which coke particles are first observed in front of the tuyere ("minimum"). Over the period shown, the raceway depth varied between 1.2 and $0.7 \mathrm{~m}$. The reduction in depth towards the end of the period was associated with the reduction in blast volume as the furnace was taken off-blast. A sudden reduction in raceway depth, which lasts for about $10 \mathrm{~min}$, may be seen approximately $20 \mathrm{~min}$

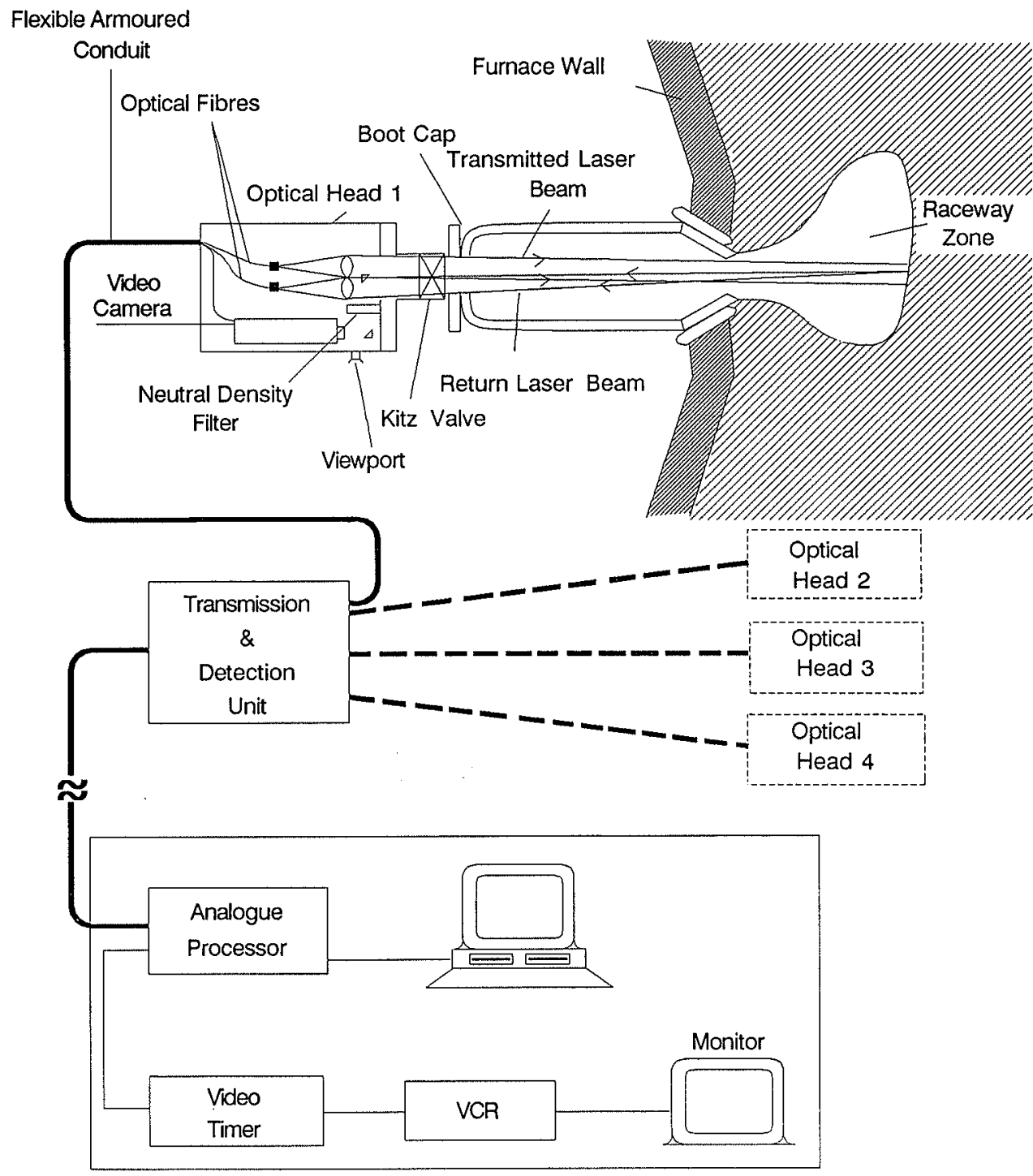

Signal processing \& display unit

Fig. 7. Schematic diagram of laser based raceway depth, temperature and visualisation measurement system shown for a single blast furnace tuyere. 


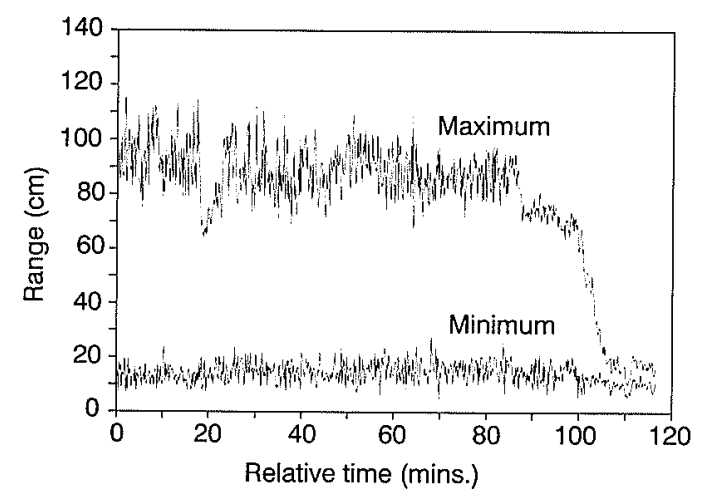

Fig. 8. Measured raceway depths for a $2 \mathrm{~h}$ period on Newcastle No. 3 blast furnace on one tuyere using the laser based measurement system.

into the period. This observation was related to the falling of a skull or a piece of cohesive zone into the raceway and its subsequent melting.

\subsection{Hearth Liquid Drainage Studies}

The effective drainage of molten slag and iron from the hearth of a blast furnace can be a major problem in the operation of large, high productivity blast furnaces. It can also affect the life of the furnace hearth. Following pioneering work by Fukutake and Okabe, ${ }^{24-26)}$ studies were undertaken at the University of New South Wales in order to provide fundamental information on liquid drainage from the hearth. ${ }^{37-42}$ )

Tanzil et al. ${ }^{37)}$ showed that when two immiscible liquids were drained from a Hele-Shaw apparatus ${ }^{41}$ ) the viscous liquid layer (analogous to the slag phase) tilted downwards towards the taphole and this led to premature termination of the cast due to gas evolution when the interface reached the taphole. This effect was also reported for single liquid drainage. ${ }^{34-36}$ ) In addition, however, Tanzil et al. ${ }^{37}$ showed that the low viscosity liquid metal phase actually drained from below the level of the taphole during the drainage process. This was an important result, since it helped to explain the observation of, for example, slag first casts on operating blast furnaces. It also showed that the single phase liquid residual ratio correlations could be inaccurate at high drainage rates.

Tanzil ${ }^{41)}$ extended the experimental studies to include transient numerical modelling of the two liquid interfaces during the drainage process, both in two and three dimensions. The resulting model was validated against the two-dimensional drainage data and then applied to the Chiba No. 6 blast furnace of Kawasaki Steel Corporation where data were available on the slag and iron flowrates. ${ }^{36)}$ The model predicted that at the end of the cast the slag and iron surfaces tilted downwards and upwards respectively towards the taphole, as shown in Fig. 9. The model also predicted considerable slag holdup at the end of the cast.

Studies on the residence time distributions of liquid in the blast furnace hearth were also undertaken at The University of Wollongong. ${ }^{42,44)}$ The work involved measurement of tracer response curves in a
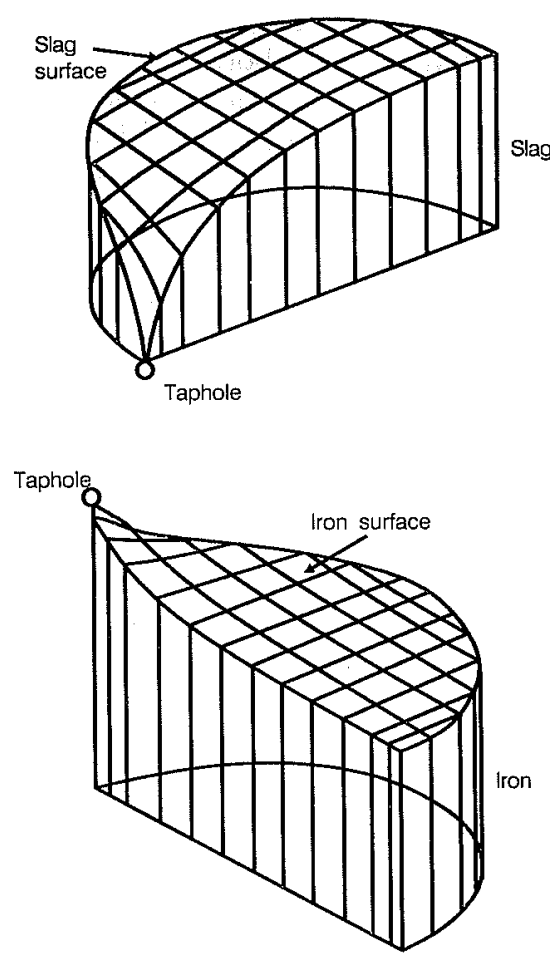

Fig. 9. Predicted shapes of the slag and iron interfaces at the end of drainage for the Kawasaki Steel Corporation Chiba No. 6 blast furnace at the furnace centreline from a three dimensional numerical model (reproduced with permission of Tanzilin').

cold scale model of a blast furnace hearth with and without coke-free layers at the base and coke-free gutters near the wall. Mini-probes were utilised to monitor the tracer concentrations throughout the bed. It was shown in the studies that the presence of different packing regions in the hearth alters the residence time distributions. It was also shown that the results from the injection of RI tracer through the tuyeres on operating furnaces cannot distinguish between a uniform coke-free layer beneath the coke bed and a coke-free gutter at the hearth periphery.

Recently, the development of a computer-based model for the prediction of hearth liquid levels in an operating furnace during casting has been progressed at BHP. Using measurements of iron and slag flow rates, the model aims to make realistic estimates of operating liquid levels and predictions of critical times such as the end of the cast and the time when the maximum liquid level occurs. Fig. 10 shows an operator interface display of the casting information and model predictions. These include the measured and predicted flowrate of iron and slag, the predicted iron and slag liquid levels and the predicted cast duration.

\subsection{Pulverised Coal Combustion}

Pulverised coal injection into the blast furnace has become a well established technology for coke replacement. Coal is not injected at present in Australia, although this situation could change depending on the price relativity between natural gas and coal. In Australia, studies have been undertaken on the 
Fig. 10.

Operator interface display of hearth liquids status.

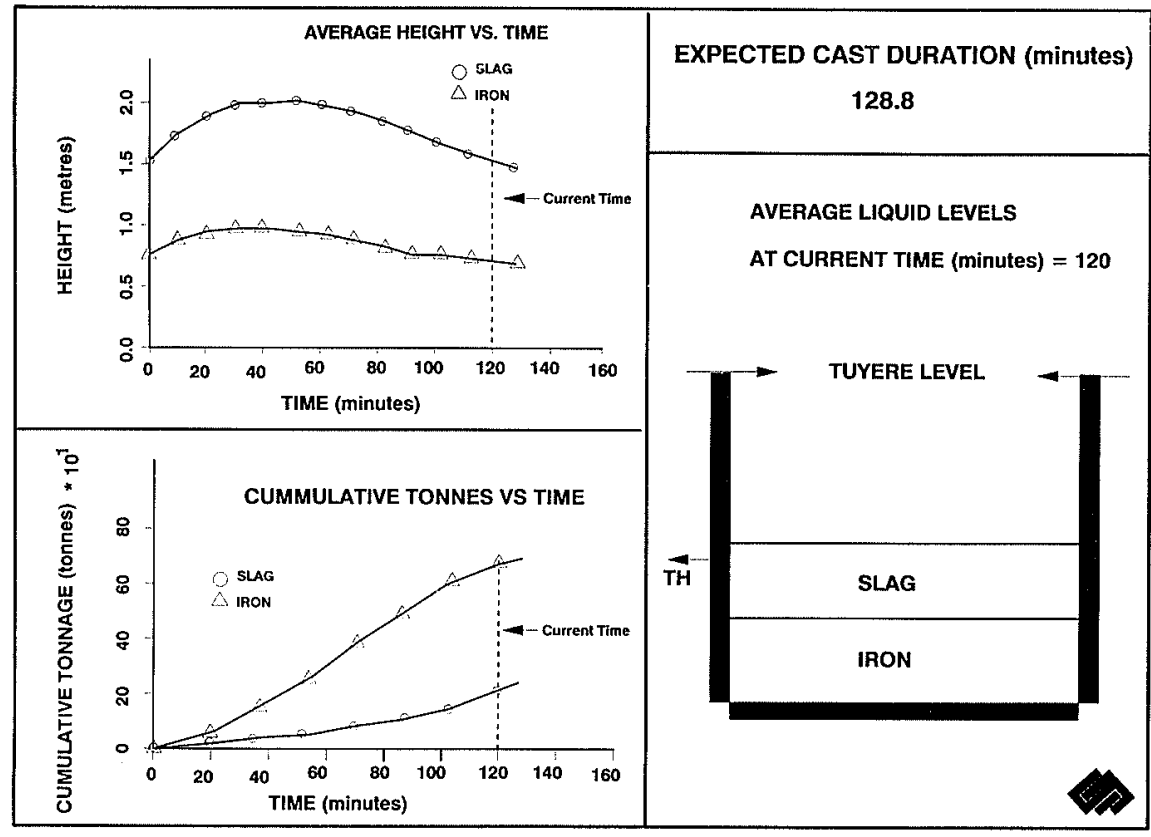

Combustion distance: $426 \mathrm{~mm}$

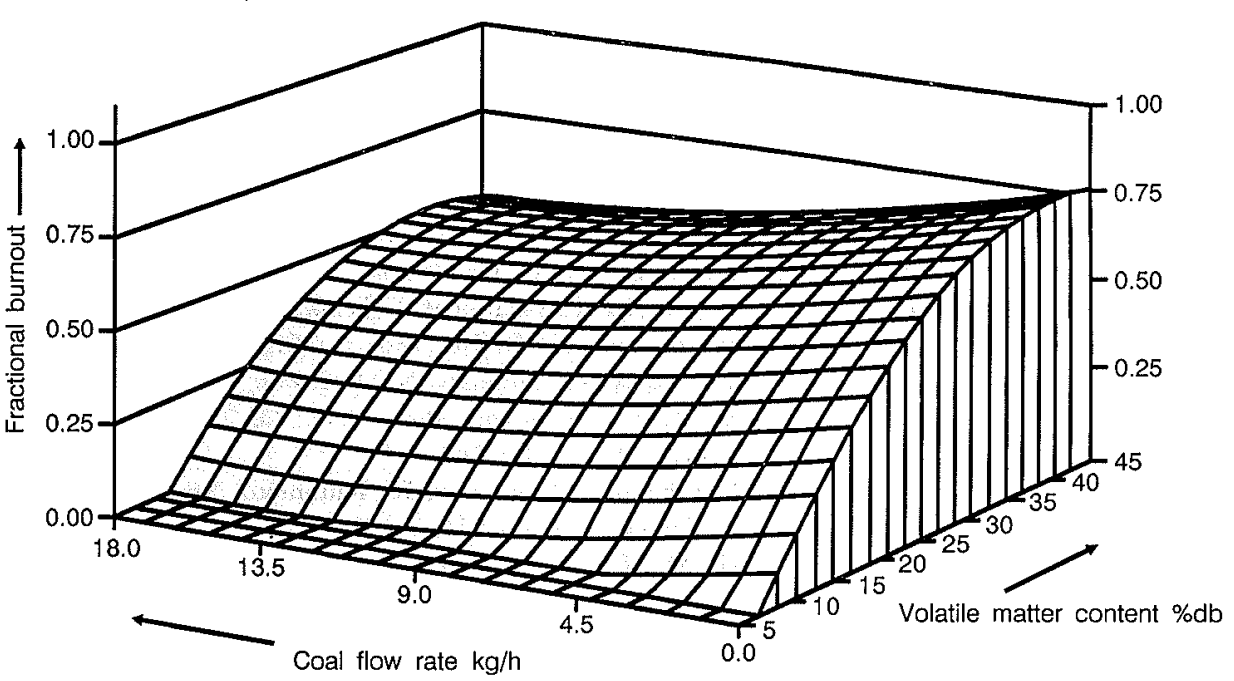

Fig. 11.

Measured coal combustibility as a function of coal injection rate and coal volatile matter for a blast temperature of $1120^{\circ} \mathrm{C}$ and a combustion distance of $426 \mathrm{~mm}$.

combustibility of pulverised coals in the blowpipe zone of the blast furnace. ${ }^{45}$ )

At the University of Newcastle, a theoretical model of the combustion process was developed together with laboratory-scale studies on coal devolatilisation. ${ }^{46,47)}$ The work confirmed the substantial influence of coal devolatilisation characteristics on the coal combustion. The model also showed that three mechanisms apart from the combustion of injectant were relevant, these being the reaction of the blast jet at the raceway walls, the entrainment of the combustible gases in the upper part of the raceway into the jet and the combustion of coke falling from the raceway roof. It was shown that significant differences in total coal burnout were predicted between low and high volatile matter coals and that a substantial proportion of the combustion of low volatile coals occurred within the raceway and not in the blowpipe.

At BHP, experimental studies were undertaken on a hot model simulating the blowpipe-tuyere region of a blast furnace. Some experimental results from this work are shown in Fig. 11. Coal burnout increased rapidly during the period of volatiles evolution and combustion and that for a typical high volatile coal burnout had reached $80 \%$ of its final value within approximately $5 \mathrm{~ms}$ of injection. At lower volatile matter contents, burnout levels were found to be much lower, and for the lowest volatile matter coals virtually no combustion had occurred in the short residence times available. Coal injection rate was also found to have a significant effect, with a gradual fall of 25 to $30 \%$ in burnout accompanying an increase in coal rate from approximately 40 to $170 \mathrm{~kg} / \mathrm{t}$ injection rate equivalent.

The effect of coal particle size was assessed for a coal of $35 \%$ volatile matter at a blast temperature of $1120^{\circ} \mathrm{C}$ and a combustion distance of $626 \mathrm{~mm}$, equivalent to approximately $10 \mathrm{~ms}$ residence time before sampling. Fig. 12 shows the coal burnout as a function of coal flow rate for these conditions. As can be seen, the effect on burnout of varying particle size within the range studied ( 37 to $62 \mu \mathrm{m}$ mean size) is 


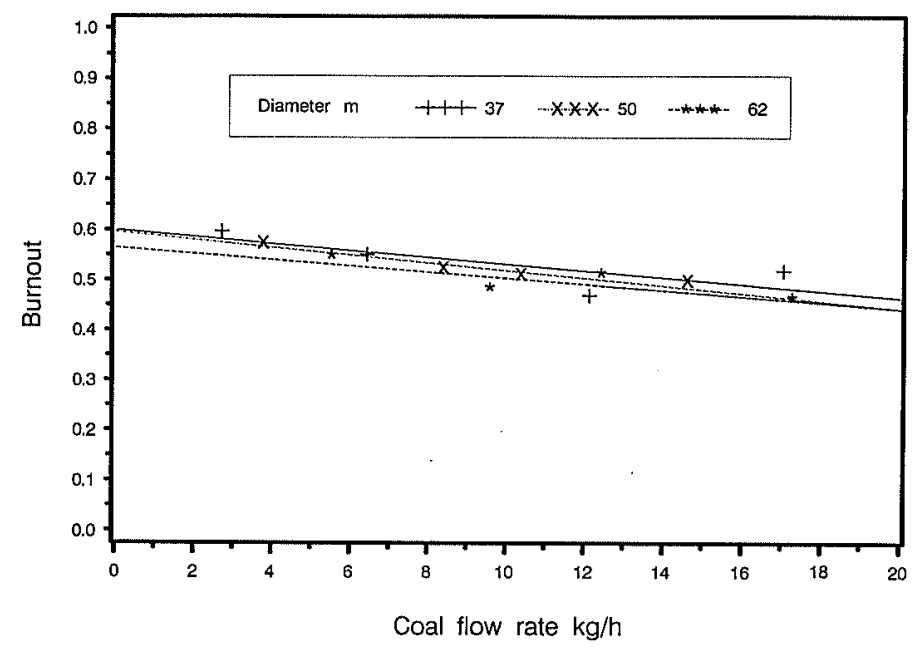

Fig. 12.

Measured coal burnout as a function of coal particle size and coal injection rate for a blast temperature of $1120^{\circ} \mathrm{C}$ and a combustion distance of $626 \mathrm{~mm}$ for a coal of $35 \%$ volatile matter. insignificant. This result implies that coals of coarser particle sizes than conventionally used could be injected into the blast furnace without adverse effects due to decreased combustibility.

\section{Conclusions}

Advances in ironmaking technology in Australia over the last decade have led to high productivity, low fuel rate blast furnace operations. This has been achieved through improvements in the raw materials charged and through improved control of the process.

Extensive use has been made of computer modelling in blast furnace research and development in Australia. This has included heat and mass balance modelling, burden distribution prediction, gas and solid flow modelling, and hearth liquid drainage simulation. In all of these cases the models have been implemented into plant practice and have provided information which has assisted operators in furnace control.

New sensors based on lasers and high speed data analysis have also been developed and applied to the measurement of furnace parameters. These have included a laser burden profiling system and a novel method for the on-line measurement of raceway characteristics. The raceway system has been shown to provide information which has hitherto been unavailable to furnace operators.

Strategic studies into the combustion characteristics of a range of coals have been carried out under conditions similar to those which occur in the blast furnace high temperature zone. These studies have shown that coal properties and injection conditions affect coal combustibility.

\section{Acknowledgements}

Many of my colleagues have contributed substantially to developments described in this review. These include Peter Burke, Campbell Cripps Clark, Kim Hockings, Lou Jelenich, Malcolm McCarthy, David Mellor, John Monaghan, Val Pinczewski, Chris Scott, Francis Tanzil, and Paul Zulli. The contributions of numerous others who have also been part of the de- scribed developments in Australia are also acknowledged.

\section{REFERENCES}

1) J. Platt, P. Ballard and D. Lathlean: Ironmaking Conf. Proc., Vol. 46, ISS-AIME, Warrendale, PA, (1987), 227.

2) J. Fletcher, P. Ballard, S. Mitchell, D. Warren and D. Bartholomew: Proc. European Ironmaking Congress, Vol. 1, Verlag Stahleisen, Düsseldorf, (1986), II-4.

3) R. Ward, D. Warren and R. Keil: Ironmaking Conf. Proc., Vol. 48, ISS-AIME, Warrendale, PA, (1989), 369.

4) K. A. Rooney, O. R. Gregory, R. J. Nightingale and K. Price: 1st International Cokemaking Congress, Vol. 1, Verlag Gluckauf GmbH, Essen, (1987), C3.

5) Y. Okuno, K. Kunimoto, S. Matsuzaki, M. Matsui and A. Suzawa: Ironmaking Proc., Vol. 44, ISS-AIME, Warrendale, $\mathrm{PA}$, (1985), 543.

6) Y. Okuno, S. Matsuzaki, K. Kunimoto, M. Isoyama and Y. Kusano: Tetsu-to-Hagané, 73 (1987), 91.

7) H. Maeda, H. Yoshimoto, J. Ichiguchi, and Y. Okuno: Seitetsu Kenkyu, (1987), No. 325, 21.

8) K. L. Hockings, J. M. Burgess, J. Monaghan, L. Jelenich, P. Zulli and W.B.U. Tanzil: Ironmaking Conf. Proc., Vol. 47, ISS-AIME, Warrendale, PA, (1988), 289.

9) S. Miwa: Rep. of Powder Technology Society of Japan, No. 26 (1960).

10) N. Standish and D. N. Collins: Powder Technology, 36 (1983), 55.

11) N. Standish and A. B. Yu: Powder Technology, 49 (1987), 249.

12) A. B. Yu and N. Standish: Powder Technology, 52 (1987), 233.

13) N. Standish and A. B. Yu: Powder Technology, 53 (1987), 69.

14) A. B. Yu and N. Standish: Powder Technology, 55 (1988), 171 .

15) N. Standish: Trans. Iron Steel Inst. Jpn., 24 (1984), B-38.

16) N. Standish: Powder Technology, 45 (1985), 43.

17) N. Standish and A. Kilic: Chem. Eng. Sci., 40 (1985), 2152.

18) N. Standish and Y. N. Liu: Powder Technology, 54 (1988), 197.

19) N. Standish: Trans. Iron Steel Inst. Jpn., 28 (1988), 683.

20) P. D. Burke and J. M. Burgess: Ironmaking Conf. Proc., Vol. 48, ISS-AIME, Warrendale, PA, (1989), 773.

21) W.B.U. Tanzil, D. G. Mellor and J. M. Burgess: Proc. of 6th Int. Iron and Steel Congress, ISIJ, Tokyo, (1990), 355. 
22) S. Ergun: Chem. Eng. Prog., 48 (1952), 89.

23) W. E. Ranz: Chem. Eng. Prog., 48 (1952), 247.

24) M. Hatano and K. Kurita: Trans. Iron Steel Inst. Jpn., 22 (1982), 448.

25) T. Usui, M. Ohmi, S. Hirashima and Y. Oshima: Proc. 6th Process Technology Conf., ISS-AIME, Warrendale, PA, (1986), 545.

26) N. Miyasaka, M. Sugata, Y. Hara and S. Kondo: Trans. Iron Steel Inst. Jpn., 15 (1975), 27.

27) W. O. Philbrook and L. O. Kirkbride: J. Met., 8 (1956), 351 .

28) J. M. Burgess: Prog. Energy and Combusion Sci., 11 (1985), 61.

29) V. Apte, T. F. Wall and J. S. Truelove: Chem. Eng. Research \& Design, 66 (1988), 357.

30) V. Apte, T. F. Wall and J.S. Truelove: AIChE J., 36 (1990), 461.

31) M. J. McCarthy, I. J. Taggart, H. Rogers, P. C. Goldsworthy and J. M. Burgess: Ironmaking Proc., Vol. 42, AIME, Pittsburgh, PA, (1983), 555.

32) M. J. McCarthy, H. Rogers, J. G. Mathieson, P. C. Goldsworthy and J. M. Burgess: Proc. Joint Symp. of ISIJAusIMM, ISIJ, Tokyo, (1983), 77.

33) A. B. Duval, J. C. Scott, P. G. Wall and J. M. Burgess: Proc. of 6th Int. Iron and Steel Congress, ISIJ, Tokyo, (1990), 405.

34) T. Fukutake and K. Okabe: Trans. Iron Steel Inst. Jpn., 16 (1976), 309.

35) T. Fukutake and K. Okabe: Trans. Iron Steel Inst. Jpn., 16 (1976), 317.

36) T. Fukutake, H. Shikata, I. Ichihara, T. Tamiya, K. Oku- mura and H. Kawarada: Ironmaking Proc., Vol. 42, AIME, Pittsburgh, PA, (1983), 567.

37) W.B.U. Tanzil, P. Zulli, J. M. Burgess and W. V. Pinczewski: Trans. Iron Steel Inst. Jpn., 24 (1984), 197.

38) W. V. Pinczewski and W.B.U. Tanzil: Chem. Eng. Sci., 36 (1981), 1039

39) J. M. Burgess, D. R. Jenkins, M. J. McCarthy, L. P. Nowak, W. V. Pinczewski and W.B.U. Tanzil: Proc. Int. Blast Furnace Hearth and Raceway Symposium, Australa. Inst. Min. Met., Melbourne, (1981), 9-1.

40) J. M. Burgess, M. J. McCarthy, D. R. Jenkins, W. V. Pinczewski and W.B.U. Tanzil: 3rd Process Technology Div. Conf., AIME, Pittsburgh, PA, (1982), 14.

41) W.B.U. Tanzil: "Blast Furnace Hearth Drainage", PhD Thesis, University of New South Wales, (1985)

42) P. Zulli: "Blast Furnace Hearth Drainage", PhD Thesis, University of New South Wales, (1990).

43) N. Standish and P.J. Campbell: Trans. Iron Steel Inst. Jpn., 24 (1984), 709.

44) N. Standish, R. Reid and J. W. Harpley: Trans. Iron Steel Inst. Jpn., 24 (1984), B-39.

45) J. M. Burgess, A. S. Jamaluddin, M. J. McCarthy, J. G. Mathieson, S. Nomura, J. S. Truelove and T. F. Wall: Proc. Joint Symposium of ISIJ-AusIMM, ISIJ, Tokyo, (1983), 129.

46) A. S. Jamaluddin, T. F. Wall and J. S. Truelove: Ironmaking Steelmaking, (1986), No. 13, 2, 91.

47) A. S. Jamaluddin, T. F. Wall and J. S. Truelove: Proc. 21 st Symposium (Int'l.) on Combustion, Combustion Inst., Pittsburgh, PA, (1986), 575. 